\title{
Развивая понимание медиа: от технологий к социальному пространству
}

Елена Вартанова

Сегодня многие исследователи, представляющие разные дисциплины, отмечают возросшее влияние медиа на жизнь общества. При этом нет не только единого представления о природе медиа, векторах и движущих силах этого явления, но и окончательной дефиниции термина.

Автор статья ставит перед собой задачу выявить основные и наиболее общие теоретические подходы к медиа, дать анализ попыток отечественных и зарубежных исследователей сформулировать определения этого явления, а также обозначить актуальные внутренние и внешние факторы их трансформации.

Ключевые слова: теория медиа, медиаисследования, журналистика, средства массовой информации, медиакоммуникации, цифровая трансформация.

DOI: 10.30547/mediaalmanah.5.2020.1224

@ Вартанова Елена Леонидовна доктор филологических наук, профессор, член-корреспондент РАО, декан факультета журналистики МГУ имени М.В. Ломоносова, главный редактор журнала «Меди@льманах» (г. Москва, Россия), eva@smi.msu.ru

\section{Медиа: поиск дефиниций}

Несмотря на отсутствие конвенциональных определений и корреляций между многими ключевыми терминами, освоенными в поле современных медиаисследований, достаточно вспомнить дискуссию о рамках понятий «медиа», «массмедиа», «средства массовой информации», «журналистика» (Вопросы теории и практики журналистики, 2016, 2017) - наибольшую сложность все еще представляет трактовка понятия «медиа», не имеющего пока поддерживаемого большинством исследователей определения (Макеенко, 2017, 2018). Проблема заключается как в сложности, многогранности и даже противоречивости самого объекта, так и в его операционализации, выявлении эмпирических показателей, его характеризующих (От теории журналистики к теории медиа, 2019: 71-126).

На первый взгляд, исторически термин «медиа» имеет достаточно понятное определение. В своей основополагающей работе «Коммуникативистика и средства информации: англо-русский толковый словарь концепций и терминов», до сих пор остающейся наиболее полным словарем терминов, соотносящим англоязычные и русскоязычные концепции, Л.М. Землянова (2004: 200) определяет медиа как: «...средства связи и передачи информации различных типов - от самых древних (языки 
жестов, дымов, барабанов, наскальных рисунков и др.) до наисовременнейших, образующих глобальные информационные супермагистрали. В особую категорию выделяются массмедиа - массовые средства информационных связей, отличающиеся особой атрибутикой и функциями».

Очевидно, что понятие "медиа» является родовым для понятия «массмедиа», которое описывается классиком медиаисследований Д. МакКуэйлом (2013: 9) и как индустрия, и как самостоятельный социальный институт. В русскоязычных исследованиях «массмедиа» часто употребляется как синоним понятия «средства массовой информации», то есть таких информационно-коммуникационных средств, как телевидение, радио, газеты, журналы, при помощи которых рекламодатели, политики общаются с широкими слоями общества (Землянова, 2004).

Продолжая эту линию, вспомним однозначные трактовки понятия «СМИ», содержащиеся в Законе РФ «О средствах массовой информации» (1991)․․․ В документе под средством массовой информации понимается «печатное издание, сетевое издание, телеканал, радиоканал, телепрограмма, радиопрограмма, видеопрограмма, кинохроникальная программа, иная форма периодического распространения массовой информации под постоянным наименованием (названием)» (ст. 2)². Конечно, в научном исследовании будет недостаточным опираться только на определение федерального закона, однако учесть его точную и понятную формулировку будет не лишним, особенно в случае, когда об определении СМИ (или массмедиа) все еще не договорились ученые.

Такая неоднозначность определения ключевых для поля медиаисследований терминов связана с рядом причин, и одной из существенных стала особенность развития академических подходов в России - традиции приоритетного внимания к журналистике, понимавшейся в условиях идеологически детерминированной публичной коммуникации и как инструмент работы с общественным мнением, и как творческая профессия, вокруг которой сформировалась газетно-издательская и телерадиовещательная система (Вартанова, 2019).

Ведущий теоретик московской школы теории журналистики Е.П. Прохоров (2009) ставил журналистику в центр исследований всей информационно-коммуникационной сферы, адресованной массовой аудитории. Он подчеркивал: «Роль центральной категории может сыграть лишь такое общее понятие, которое раскрывает специфичность, фундаментальную особенность изучаемого предмета - журналистики, а потому является характеристичным как для журналистики в целом, так и для всех сторон, шагов деятельности в ней. Будучи внешне простым, очевидным для "наблюдателя", в свернутом виде оно содержит в себе, как в зародыше, все богатство, разнообразие и сложность рассматриваемого явления... Основным требованиям центральной категории отвечает понятие "массовая информация". Не случайно и наиболее употребительным синонимом к термину "журналистика" выступает словосочетание "средства массовой информации". Иногда к этому словосочетанию добавляют "<...> и пропаганды" - это свидетельствует лишь о том, что термин "информация", к сожалению, употребляется не только в научно-специальном значении, но и в традиционном узкожурналистском смысле (как обозначение кратких некомментированных сообщений об актуальных новостях и соответствующих жанров - заметки, отчета, интервью, репортажа, часто именуемых "информационными")» (Прохоров, 2009: 13-14).

Е.П. Прохоров $(1984,2004,2012)$ достаточно широко понимал журналистику, отождествляя ее с системой СМИ (или даже СМИП - системой массовой информации и пропаганды, как это было приято 
в советской теории журналистики). Он рассматривал «информацию» не только как продукт журналистского творчества, но и как содержание каналов коммуникации в самом широком смысле. Правда, в этом и других описаниях объектно-предметной области он ограничивал поле массмедиа только текстами профессиональных журналистов, счем, конечно, трудно согласиться, поскольку из фокуса его внимания выпадали процессы их производства и распространения, то есть индустриальная и технологическая составляющая СМИ как системы.

Несколько позже более точную и широкую формулировку определения "медиа» дал известный теоретик санкт-петербургской школы С.Г. Корконосенко (2001: 4), который подчеркивал: «В американской и частично европейской лексике в сходном значении используется понятие mass media, массмедиа (или просто media, медиа). В английском словаре Webster мы находим следующую статью: “mass media (1923) - средство коммуникации (газеты, радио или телевидение), предназначенное для того, чтобы обращаться к массе людей". Нетрудно заметить, что перед нами фактически то же явление, которое выше называлось СМК. Однако с 20-х годов, которые упоминаются в словаре как момент введения термина в употребление, его реальное содержание не могло не измениться». В своей формулировке С.Г. Корконосенко обращает внимание на такую важную особенность массмедиа, как наличие процесса технологического опосредования (медиации), при передаче информации (содержания), в том числе и журналистского текста, массовой аудитории.

В последние годы отечественные исследователи, осмысляя медиа, стремятся не столько дать формулировки этого явления, сколько найти эмпирические подтверждения его теоретического смысла, трансформировать абстрактное понятие «медиа» в конкретные реалии, индикаторы, модели. Интуитивно понятный, термин описывается и как совокупность средств коммуникации, и как пространство, и как среда, и как система (Бузин, 2012; Жилавская, 2011).

Однако четких формулировок ученые все же не дают. Напротив, на широком поле понятия «медиа» они, как отмечает Н.Б. Кириллова (2011: 8), стремятся сузить свой предмет исследования, сделав его более сфокусированным. Таким образом, возникают его более узкие, зато конкретные объектно-предметные поля, выделяемые по разным основаниям: медиареальность, медиаполитика, медиаэкономика, медиамаркетинг, медиаменеджмент, медиакультура, медиаобразование (Вартанова, 2003; Кириллова, 2006; Гуревич, Иваницкий, Назаров, Щепилова, 2007; Фатеева, 2007; Дзялошинский, 2015; Кириллова, 2015; Вырковский, 2016; Ульбашев, 2017).

Отсутствие однозначного определения термина «медиа» и попытка скорее описать его, а не загнать в жесткие рамки единственной и окончательной дефиниции - это очевидная практика не только российских, но и зарубежных медиаисследователей. Приведем в подтверждение только две недавние работы. Т. Миллер и М. Крэйди (2016) определяют феномен медиа следующим образом: «Мы используем термин "медиа" как слово-портмоне для описания множества культурных и коммуникационных машин (инструментов) и процессов, которые связывают людей, процессы, институты, значения и власть в материальном мире.

Медиа [одновременно составлены из] и представляют собой:

- технологии, которые формируют их возможные условия,

- политику, которая определяет область их деятельности,

- жанры, которые организуют тексты в форме драмы, музыки, спорта, информации и так далее,

- работников, которые производят медиатексты путем представления [performance] и записи, 
• аудиторию, которая получает и интерпретирует производимые тексты, и окружение, на которое воздействует создание, использование и составные части медиа» (Miller, Kraidy, 2016: 4).

Р. Колкер (2009: 12), подчеркивая постоянную изменчивость содержания термина, определяет его следующим образом: «Медиа относятся к множеству ориентированных на получение прибыли и технологически зависимых компаний и продуктов, которые занимаются доставкой новостей, радио, музыкой, звукозаписью, рекламой, кинофильмами, телевидением и множеством цифровых передач и взаимодействий».

\section{От содержания к технологиям: осмысляя подходы Г.М. Маклюэна}

Следует признать, что основную роль в формировании теоретических подходов к медиа сыграли не просто зарубежные научные школы, а непосредственно школа технологического детерминизма. Ее корни уходят в середину XX в. - время активного становления в медиасистеме, в широком поле социальной коммуникации нового для своего времени СМИ - телевидения. Рождение этой школы напрямую связано с именем Г.М. Маклюэна.

По мере становления телевидения представления Маклюэна о технологиях информационной среды, об их воздействии на передаваемое аудитории содержание получили значительный импульс. Он концептуализировал медиа, понимавшиеся до этого момента как технологии распространения содержания, как новую технологическую и, главное, культурную среду, которая преобразовывает жизненные практики и повседневность человека, его ценности (Маклюэн, 2003). Поставив перед собой задачу сформулировать «понимание медиа» (Understanding Media - так называется одна из самых известных его книг), Маклюэн предложил рассматривать медиа как средства коммуникации, но обязательно в их тесной связи с человеком. Уже в 1960 гг. он назвал медиа "расширениями человека» (extentions of men) (MacLuhan, 1964). При этом сами медиатехнологии появляются и развиваются в общественном пространстве всегда в ответ на общественный запрос (Williams, 1975).

Осмысливая роль медиатехнологий, Маклюэн сформулировал одно из самых известных положений своего концептуального аппарата. Его классическая фраза The Medium Is the Message (буквальный перевод: «Посредник есть сообщение») (McLuhan, 1964: 8-9) не может быть понята на русском языке однозначно. Возможные интерпретации основываются на том обстоятельстве, что во фразе обозначены два основных понятия медиа - канал и содержание. Medium здесь, очевидно, выступает «посредником», но не только. Слово может обозначать и «проводника», и «передатчик», и «канал». A message - это и сообщение, и послание, и содержание.

Исследователь творчества М. Маклюэна И.Б. Архангельская (2009: 33), подчеркивая, что форма медиа влияет на смысл сообщения, и в результате на сознание, пишет: «Анализ толкований данного высказывания <...> доказывает тот факт, что многие положения теории Маклюэна могут быть восприняты неоднозначно. Однако главным, на наш взгляд, в формуле the medium is the message является технологический подход к средствам коммуникации. Сообщение может быть по-разному понято и расшифровано, может иметь иное значение в зависимости от того, в какую оболочку оно упаковано: рукопись, печатный текст, устное высказывание, радио или телевизионную передачу (причем жанр текста и передачи влияет на смысл сообщения)».

Продолжая интерпретировать идеи Маклюэна, можно предположить, что медиум, (канал), передавая сообщение, и определяетто, как оно, сообщение, воспринимается аудиторией. То есть контент подвергается воздействию отличительных свойств канала, 
и канал в значительной степени детерминирует контент. В дальнейшем развитие медиа как социальной системы и отрасли в ее индустриальной практике подтвердило блестящую догадку ученого о двусоставной сути медиа, о значении для аудитории не только передаваемого содержания, но и передающего канала, об их тесной взаимосвязи.

Правда, именно технологическое развитие передающей и принимающей инфраструктур медиа привело в дальнейшем к «отделению» контента от канала, создав новые условия для их взаимодействия. Однако двухсоставная природа медиа постоянно подтверждалась, что привело не только к формированию структур производства контента (редакции, киностудии, звукозаписывающие компании, блогеры) и распространителей (вещатели, кабельные и спутниковые компании, телекоммуникационные сети), но и к различным их конфигурациям, включающим современные цифровые платформы и экосистему медиа (Айрис, Бюгин, 2010).

М. Маклюэн осмысливал феномен медиа на протяжении многих лет. Через «метод четырех эффектов», предложенный в конце жизни, он попытался проанализировать как феномен самих медиа, так и их основные воздействия на человека. Он предположил, что в результате четырех эффектов поиск нового, отмена старого, его моральное устаревание и усиление нового, когда медиа выступают и качественным усилением нашего внутреннего мира, и расширением внешнего, - медиа превращаются в инструмент самопознания. Тем самым, в последних работах выдающегося теоретика медиа подчеркивалось, что медиа есть многосоставный феномен, включающий:

- технологии (связи);

- артефакты (устройства для приема);

- слова (тексты);

- научные теории открытий и изобретений человечества (McLuhan M., McLuhan E., 1992).
Медиасреда сегодня отличается более сложными процессами, чем в середине XX в., когда М. Маклюэн разрабатывал свои подходы к медиа. Но хотя новая реальность существенно усложнилась, медийная взаимосвязь содержания и канала, контента и технологий сохраняет свою неразрывность. Прежде всего потому, что два главных компонента - канал распространения и распространяемое сообщение, т.е. новостное, аналитическое, просветительское, развлекательное содержание - остаются ключевыми в современных медиаструктурах и процессах.

\section{От технологий и содержания - к социальному пространству}

Рассматривая термин «медиа», мы подошли к вопросу о многоаспектности его определения. Сам объект изучения - медиа имеет синтетический характер, интегрирует явления, институты, процессы, «действующих лиц»/стейкхолдеров разного генезиса и природы (Flew, 2018). Как неоднократно отмечал М. Маклюэн , эффективное изучение средств массовой коммуникации объединяет изучение технических средств передачи содержания с изучением самого содержания и культурных контекстов, в которых оно распространяется и потребляется.

Современные медиа - это достаточно широкое понятие, обозначающее и новый тип социального пространства, и общественный институт, границы которого постоянно меняются, и значительную в современной экономике отрасль (Отечественная теория медиа: основные понятия, 2019: 109-110). Медиа в своем существовании интегрируют разные социальные среды, пласты общественной и индивидуальной коммуникации, благодаря чему в обществе формируется неотъемлемый компонент социальной реальности - общественная (публичная) сфера.

Предложенная в 1980 гг. немецким философом и социологом Ю. Хабермасом концепция общественной (или в дословном 
переводе с немецкого - публичной) сферы, поставила массмедиа в центр общественной жизни. СМИ, по мнению ученого, выступают и как регулятор социальной жизни, и как форум, площадка для формирования общественного мнения посредством дебатов между разными субъектами политического процесса (Habermas, 1991).

Для Ю. Хабермаса институционализированность массмедиа оказалась одновременно и достоинством, и недостатком. С одной стороны, как индустриально организованные предприятия с налаженными системами распространения они смогли обеспечить широкую аудиторию журналистскими произведениями на актуальные темы, что было необходимо для активного участия избирателей в выборах и формирования общественного мнения. С другой как субъекты рынка медиапредприятия, редакции оказались под заметным влиянием собственников, рекламодателей и впоследствии пресс-служб политиков, что постоянно становилось препятствием непредвзятой работе журналистов. Несмотря на сложности, существующие в практической деятельности медиа, именно идеи Ю. Хабермаса о роли СМИ в обществе дают возможность рассматривать их как своего рода социальное пространство, социальную среду, формируемые в процессе взаимодействия медиатехнологий, профессионалов медиаиндустрии и аудитории.

Медиа - это, прежде всего, среда обращения текстов, содержащих общественно значимую информацию, присутствующие в социуме идеи, смыслы, ценности, что ставит контент и каналы медиа в тесную связь с обществом (Habermas, 1991). Общественная сфера и есть сфера бытования, функционирования социальной коммуникации, и этот подход актуализирует роль медиа в общественных процессах, поскольку они, репрезентируя политику и экономику, создают представления социума о различных общественных явлениях (Habermas, 1991). Следует признать весьма значимыми и медиаотражения, освещение в медиа культуры, объединяющей в едином пространстве не только высокую и низкую (развлечение) культуру и СМИ, но и свободное время людей (Черных, 2007; Основы медиабизнеса, 2014). Это напрямую выводит медиа на формирование человеческого капитала и идентичности страны.

Еще одна важная отличительная особенность медиа - это индустриальная организация их производства и распространения, которая привела к становлению и функционированию значимого сегмента современной экономики (Kung, Picard, Towse (eds.), 2008). Сегодня он объединяет медиабизнес (систему газетно-журнальных, телерадиовещательных, кабельных и спутниковых компаний, информационных агентств, продакшн- и киностудий, и т.п.), а также телекоммуникационные, ИТкомпании. Это значительный рынок труда, который представлен множеством работников основных и смежных медиапрофессий (Медиасистема России, 2020). Медиаиндустриюуже долгие годы отличаюттесные связи с предприятиями информационнокоммуникационного сектора, что приводит к их интеграции, конвергенции, появлению нового сегмента современной экономики (Интернет-СМИ, 2010).

Медиа в последнее время также должны быть рассмотрены не только как информационная и коммуникационная среда, но и как коммуникационный процесс. Вероятно, это одно из самых актуальных и новых представлений как о самих медиа, так и об обществе в целом. Если изначально медиа представляли собой единство производства и доставки содержания, то сегодня следует говорить о расширении понятия. Медиа уже больше, чем только индустриальная структура, создающая содержание (новости, развлечения), и больше, чем система его распространения.

Медиа превращаются в общественных коммуникаторов, в систему, обеспечивающую не только однонаправленный 
коммуникационный процесс (от журналистов и авторов текстов для медиа - к аудитории), но и двусторонний, все чаще и многосторонний коммуникационный процесс (от многочисленных производителей содержания к фрагментированной аудитории и обратно, а также между аудиториями и непрофессиональными авторами) (Землянова, 2012; Van der Haak, Parks, Castells, 2012; Кин, 2015; Кастельс, 2016).

Это приводит к тому, что все чаще артикулируется роль медиа как среды обитания, существования современного человека, как неотъемлемой части человеческого бытия (Deuze, 2012), а также становления человека медийного - новой социальной ипостаси, определяемой тесными связями индивида с медиа, даже его зависимостью от них (Вартанова, 2019: 172-173). На всех этапах жизни людей медиа как один из значимых социальных институтов оказываются включенными в процесс социализации, что особенно характерно для молодежи, и это придает им особый статус среди других ключевых социальных институтов, оказывающих влияние на воспитание и образование будущих поколений (Dunas, Vartanov, 2020).

\section{Медиа: актуальные факторы влияния}

Медиа - один из важнейших институтов и в то же время ключевых социальных пространств современного общества. Они представляют собой крайне сложное явление, в котором обнаруживается переплетение информационно-коммуникационных технологий, индустриальных производственных структур, субъектов различной природы, связанных многосторонними, многоуровневыми и разнонаправленными (взаимо)отношениями (McQuail, 2010; Шкондин, 2015: 335-338).

Изучая исторические этапы развития этого феномена, исследователи подчеркивали, что трансформация, переходность всегда были присущи медиа именно в силу их неразрывной связи с общественной динамикой, прямой зависимостью от социального развития или даже регресса (Землянова, 2012; Кастельс, 2000, 2016; Кин, 2015). Как следствие, именно изменчивость медиа, обусловленная воздействием на них социальных процессов, была признана их имманентной характеристикой, определяемой такими факторами, как:

- общественная суть медиа и журналистики, проявляющаяся в их неразрывной связи с национальным государством, в котором они функционируют как важный социальный институт, в их зависимости от направления и динамики развития общества, ускоряемыми, в свою очередь, развитием информационно-коммуникационныхтехнологий и медиакоммуникаций (МакКуэйл, 2013; Маклюэн, 2003; Negroponte, 1996);

- запрос общества, его различных групп на достоверную, полную, объективную общественно-политическую новостную повестку и ее анализ (Прохоров, 2009; Лазутина, 2010; Свитич, 2000);

- потребности современного человека понимать окружающий мир в процессах социализации и самореализации через массовую или немассовую медиакоммуникацию (Винтерхофф-Шпурк, 2007; Богомолова, 2010; Dunas, Vartanov, 2020).

Среди основных общественных тенденций, которые определили в последние годы развитие медиа и расширение их социального влияния, необходимо выделить несколько ключевых.

Во-первых, это цифровая трансформация. Так, в экономике возросло использование цифровой информации как экономического ресурса, заметно выросло применение цифровых телекоммуникационных сетей (Negroponte, 1996; Уэбстер, 2004; Кастельс, 2016). Политика стала важнейшим объектом процесса медиатизации (Гуреева, 2018), образование потребовало от обучающих и обучаемых нового уровня цифровой медиаграмотности, и современные культурные институты и процессы в значительном объеме переместились 
в цифровую медиасреду (Flew, 2014; Couldry, Hepp, 2018).

Повсеместная цифровизация заметно преобразила и медиаиндустрию (Cunnigham, Flew, Swift, 2015), и национальные медиасистемы (Медиасистема России, 2020). Объединение в цифровом пространстве технологических платформ, сервисов, контента и индивидуальных медиаустройств, включающих пользователей в это пространство, привело к процессу слияния медиаиндустрии с телекоммуникационной и компьютерной отраслями, к формированию экосистемы «ИТ - телекоммуникации - медиа» (De Prato, Sanz, Simon (eds.), 2004).

Во-вторых, это процесс глобализации, одновременно, но по-разному проявляющийся во всех странах (Robertson, 1992). Он продемонстрировал в глобальном масштабе стремление как к геополитическому доминированию Соединенных Штатов Америки, так и к возникновению множественных новых центров силы. Их часто определяют как «развивающиеся рынки», как процесс "роста остальных» в противовес все еще влиятельным старым центрам глобализации, прежде всего «богатому Северу» (О^ Нил, 2013; Шарма, 2013).

В результате усиления в мировой политике влияния стран Азиатско-Тихоокеанского региона, Ближнего Востока, Латинской Америки проявилась асимметричная глобализация, в контексте которой возросло значение "мягкой силы», или, точнее, "мягкой власти» - именно такой смысл вкладывал в термин Д. Най, предложивший его академическому сообществу. Мягкая сила, понимаемая как деятельность страны по формированию симпатий к ней, опирается не на инструменты принуждения или насилия, а на продвижение, пропаганду своих достижений в духовной культуре, интеллектуальной сфере (Ткачева, 2019: 93-94). Именно национальные медиасистемы, национальный комплекс каналов и содержания медиа, продвигая культуру, ценности и идеологию страны в глобальном коммуникационном пространстве, стали ключевым инструментом мягкой силы, способствующим усилению международного культурного влияния старых и новых лидеров глобального мира (Nordenstreng, Thussu, 2015).

В этой связи интересен пример региональных медиахабов - сосредоточенных в крупных городах медиакорпораций, производящих огромные объемы аудиовизуального контента для телевидения, киноиндустрии, онлайн-сервисов. Индийский Болливуд, пекинский и шанхайский Чайнавуд, студии «Глобу» в Бразилии, работающие для Лузофонии - португалоязычных стран мира, русскоязычное сериальное и кинопроизводство в Москве стали новыми игроками международного медиабизнеса. Возникнув в ответ на потребности национальных медиасистем в аудиовизульном контенте, они привнесли и в глобальное медиапространство национальное, культурное и языковое своеобразие, поскольку сформировали своеобразный ответ стран - членов БРИКС англоязычной глобализации рынка контента. Роль этих стран стала особенно показательной, поскольку именно медиа - как содержание, индустрия и технологии - превратились в новые инструменты формирования и продвижения позитивного образа страны (Ткачева, 2019).

В-третьих, это "восстановление» роли национального государства в общественных процессах. Реинтерпретация значения национального исторического развития и культуры как факторов, оказывающих заметное влияние и на современный уровень развития стран и наций, все чаще звучит в социальных науках (Liebowitz, Margolis, 1999; Казакова, 2012). Значение исторической памяти, зависимость состояния общества от траекторий предшествующего развития экономического, политического, культурного - становятся важными аргументами в объяснении национальной специфики государств, несмотря на общие для всех 
стран процессы глобализации, унификации политики и технологической конвергенции (Норт, 1997).

Этот подход возвращает нас к дискуссии о национальных медиасистемах, их схожести и особенностях, универсальности их индикаторов и отличиях проявления последних в отдельных странах, а также об общности и различиях стандартов, этики и редакционных культур журналистики (Вартанова, 2019).

Одновременно с сильной зависимостью медиасреды от общественного развития в последнее время усиливаются внутренние процессы трансформации медиа, что приводит к приобретению ими нового статуса в общественной жизни. К этим процессам следует отнести:

- усиление структурных противоречий, проявляющихся в столкновении глобального, иностранного и национального медиакапитала, часто отражающееся в нарастании различий в международном и национальном законодательстве в области СМИ (Thussu, 2019);

- возникновение противоречий в логике производства содержания: между глобальной и национальной повесткой дня; в области профессиональных стандартов: между новостями и мнениями в журналистских произведениях, между новостями, созданными журналистами, и так называемыми «фейками», отражающими или непрофессиональность пользовательского контента, или растущую ангажированность медиа в условиях информационных противостояний в цифровой среде (Лабуш, Пую, 2019);

- становление различий в медиапотребительских привычках аудитории, что вырастает из поколенческих и стилевых расколов «цифровой молодежи» и более взрослой аудитории традиционных медиа, отражающих новые формы и уровень фрагментации массовой аудитории (Bourdon, Méadel, 2014; Dunas, Vartanov, 2020).

Процесс цифровизации медиа как институтов и предприятий производства социально значимого контента, каналов его распространения и платформ доступа к информации и коммуникации, по мнению исследователей, оказал наибольшее воздействие и на природу средств массовой информации, и на медиабизнес, и на взаимоотношения медиапрофессионалов и аудитории (Flew, 2014; Küng, Picard, Towse (eds.), 2008; Fenton, 2009; Doctor, 2010; FrauMeigs, 2007).

Диффузия медиаинноваций и «технологическое разрушение» (Rogers, 1962) традиционных СМИ, принципов и систем их редакционного производства, доставки содержания аудитории, перегруппировка рекламных каналов с явным оттоком рекламы оттрадиционных массмедиа (газеты, журналы, телерадиовещание) в сторону поисковых систем, социальных сетей, видеохостингов и мессенджеров стали поистине глобальными изменениями, коснувшимися природы и функций медиа во всех национальных контекстах.

\section{Заключение}

Исходя из анализа теоретических подходов, мы предлагаем рассматривать медиа и как пространство, и как экономическую систему, и как процесс. Мы считаем, что медиа - это:

- опосредованное медиатехнологической инфраструктурой информационное и коммуникационное социальное пространст-во, интегрирующее репрезентации и функционирование политики, экономики, культуры, общественного мнения и являющееся одновременно особой символической системой, в рамках которой складываются культурные практики разнонаправленных взаимодействий субъектов;

- институционализированные предприятия, обеспечивающие производство и распространение контента (новости, развлечения, просвещение), отвечающего на общественный запрос в информации и коммуникации, а также неинституционализированные/ 
непрофессиональные авторы, выходящие в медиасреду благодаря широкодоступным медиатехнологиям;

- процессы массовой, межгрупповой и индивидуальной коммуникации на глобальном и национальном уровнях, подверженные специфическим формам медиарегулирования и порождающие актуальные формы медиаполитики.
Очевидно, что предложенные в данной статье описания и дефиниция не могут рассматриваться как окончательные. Но они могут и должны обсуждаться в академическом сообществе, поскольку расширение поля медиа продолжается, а значение их в информационных и коммуникационных практиках современного общества только возрастает.

\section{Примечания}

1 Федеральный закон от 27.12.1991 № 2124-1 (ред. от 02.12.2019) «О средствах массовой информации». Режим доступа: www.consultant.ru/document/cons_doc_ LAW_1511/ (дата обращения: 22.10.2020).

2 Там же.

\section{Библиография}

Айрис А., Бюген Ж. Управление медиакомпаниями: реализация творческого потенциала. М.: ИД «Университетск. кн.»; АНО «ШКИМБ», 2010.

Архангельская И.Б. Герберт Маршал Маклюэн: от исследования литературы к теории медиа: автореф. дис. ... д-ра филол. наук. М., 2009.

Богомолова Н.Н. Социальная психология массовой коммуникации. М.: Аспект Пресс, 2010.

Бузин В.Н. Социальное управление российским медиапространством. Системнодеятельностный подход. М.: ЮНИТИ-ДАНА, 2012.

Вартанова Е.Л. Медиаэкономика зарубежных стран. М.: Аспект Пресс, 2003.

Вартанова Е.Л. Теория медиа: общественный дискурс. М.: Фак. журн. МГУ; Изд-во Моск. ун-та, 2019.

Винтерхофф-Шпурк П. Медиапсихология. Основные принципы. Харьков: Гуманит. центр, 2007.

Вопросы теории и практики журналистики. 2016. Т. 5. № 4.

Вопросы теории и практики журналистики. 2017. Т. 6. № 1.

Вопросы теории и практики журналистики. 2017. Т. 6. № 3.

Вырковский А.В. Редакционный менеджмент в печатных и онлайновых массмедиа: процессный подход. М.: МедиаМир, 2016.

Гуревич С.М., Иваницкий В.Л., Назаров А.А., Щепилова Г.Г. Основы медиамаркетинга. М.: МедиаМир, 2007.

Гуреева А.Н. Концептуализация процесса медиатизации в России и за рубежом // МедиаАльманах. 2018. № 5. C. 24-31. DOI: 10.30547/mediaalmanah.5.2018.2431

Дзялошинский И.М. Современное медиапространство России. М.: Аспект Пресс, 2015.

Жилавская И.В. Медиаповедение личности. Обретение смысла // Медиаскоп. 2011. Вып. 2. Режим доступа: http://www.mediascope.ru/node/786 (дата обращения: 22.09.2020).

Землянова Л.М. Журналистика и коммуникативистика. М.: МедиаМир, 2012.

Землянова Л.М. Коммуникативистика и средства информации: англо-русский толковый словарь концепций и терминов. М.: Изд-во Моск. ун-та, 2004. 
Интернет-СМИ: Теория и практика / под ред. М.М. Лукиной. М.: Аспект Пресс, 2010.

Казакова В.И. Концептуализация «Path Dependence» в современной социальной науке // Вестн. НПУ им. Р.Е. Алексеева. Сер.: Управление в социальных системах. Коммуникативные технологии. 2012. № 3. С. 6-16.

Кастельс М. Власть коммуникации / пер. с англ. Н.М. Тылевич; науч. ред. А.И. Черных. М.: ИД ГУ ВШЭ, 2016.

Кастельс М. Информационная эпоха: экономика, общество и культура. М.: ИД ГУ ВШЭ, 2000.

Кин Д. Демократия и декаданс медиа / пер. с англ. Д. Кралечкина; науч. ред. А. Смирнова. М.: ИД ГУ ВШЭ, 2015.

Кириллова Н.Б. Медиакультура: от модерна к постмодерну. 2-е изд., перераб. и доп. М.: Акад. проект, 2006.

Кириллова Н.Б. Медиаполитика государства в условиях социокультурной модернизации: учеб. пособие. Екатеринбург: Изд-во Уральск. ун-та, 2015.

Кириллова Н.Б. От медиакультуры к медиалогии // Культурологический журнал. 2011. № 4 (6). Режим доступа: http://docplayer.ru/36613427-2011-4-6-udk-kirillova-nb-soderzhanie-ot-mediakultury-k-medialogii.html (дата обращения: 22.09.2020).

Корконосенко С.Г. Основы журналистики. М.: Аспект Пресс, 2001.

Лабуш Н.С., Пую А.С. Медиатизация экстремальных форм политического процесса: война, революция, терроризм. СПб.: Изд-во СПбГУ, 2019.

Лазутина Г.В. Основы творческой деятельности журналиста. М.: Аспект Пресс, 2010.

Макеенко М.И. Развитие теорий медиа в российских научных журналах в 2010-е гг.: результаты первого этапа исследований // Вестн. Моск. ун-та. Сер.: 10. Журналистика. 2017. № 6. С. 3-31.

Макеенко М.И. Направления трансформации теоретических подходов в российских исследованиях влияния цифровизации на медиа // Медиаскоп. 2018. Вып. 3. Режим доступа: http://www.mediascope.ru/2463 DOI: 10.30547/ mediascope.3.2018.1 (дата обращения: 22.10.2020).

МакКуэйл Д. Журналистика и общество. М.: МедиаМир; Фак. журн. МГУ, 2013.

Маклюэн Г.М. Понимание медиа: Внешние расширения человека / пер. с англ. В. Николаева. М.: Жуковский: КАНОН-пресс-Ц; Кучково поле, 2003.

Медиасистема России / под. ред. Е.Л. Вартановой. М.: Аспект Пресс, 2020.

Норт Д. Институты, институциональные изменения и функционирование экономики / пер. с англ. А.Н. Нестеренко. М.: Фонд эконом. кн. «Начала», 1997.

О'Нил Дж. Карта роста. Будущее стран БРИК и других развивающихся рынков. М.: Альпина Бизнес Букс; Манн, Иванов и Фербер, 2013.

Основы медиабизнеса / под ред. Е.Л. Вартановой. М.: Аспект Пресс, 2014.

От теории журналистики к теории медиа. Динамика медиаисследований в современной России / под ред. Е.Л. Вартановой. М.: Изд-во Моск. ун-та, 2019.

Отечественная теория медиа: основные понятия. Словарь / под ред. Е.Л. Вартановой. М.: Фак. журн. МГу; Изд-во Моск. ун-та, 2019.

Прохоров Е.П. Введение в теорию журналистики. М.: Аспект Пресс, 2009.

Прохоров Е.П. Искусство публицистики. М.: Сов. писатель, 1984.

Прохоров Е.П. Наука о журналистике должна иметь четкую структуру // МедиаАльманах. 2004. № 2-3 (6). С. 6-9.

Прохоров Е.П. Терминологический аппарат - понятийно-смысловой скелет науки // Вестн. Моск. ун-та. Сер. 10: Журналистика. 2012. № 1. С. 27-38. 
Свитич Л.Г. Феномен журнализма. М.: ИКАР, 2000.

Ткачева Н.В. Развитие массмедиа в контексте эволюции политики мягкой силы Китая. М.: Вестн. Моск. ун-та. Сер. 10: Журналистика. 2019. № 6. С. 94-128. DOI: 10.30547/vestnik.journ.6.2019.94128

Ульбашев А.Х. Основы медиарегулирования. М.: Infotropic Media, 2017.

Уэбстер Ф. Теории информационного общества / под ред. Е.Л. Вартановой. М.: Аспект Пресс, 2004.

Фатеева И.А. Медиаобразование: теоретические основы и практика реализации. Челябинск: Изд-во Челябинск. гос. ун-та, 2007.

Черных А.И. Мир современных медиа. М.: ИД «Территория будущего», 2007.

Шарма Р. Прорывные экономики. В поисках следующего экономического чуда. М.: Манн, Иванов и Фербер, 2013.

Шкондин М.В. Информационный потенциал общества и концепты целостности медиасистемы // Вопросы теории и практики журналистики. 2015. Т. 4. № 4. С. 335-348.

Bourdon J., Méadel C. (2014) Television Audiences Across the World. Deconstructing the Ratings Machine. London: Palgrave Macmillan.

Couldry N., Hepp A. (2018) The Mediated Construction of Reality. London: John Wiley\&Sons. Cunningham S., Flew T., Swift A. (2015) Media Economics. Basingstoke: Palgrave Macmillan. De Prato G., Sanz E., Simon J. P. (eds.) (2004) Digital Media Worlds. The New Economy of Media. New York: Palgrave Macmillian.

Deuze M. (2012) Media Life. Cambridge: Polity Press.

Doctor K. (2010) Newsonomics: Twelve New Trends That Will Shape the News You Get. New York: St. Martin's Press.

Dunas D., Vartanov S. (2020) Emerging Digital Media Culture in Russia: Modeling the Media Consumption of Generation Z. Journal of Multicultural Discourses 15 (2): 186-203.

Fenton N. (2009) New Media, Old News: Journalism and Democracy in the Digital Age. London: Sage.

Flew T. (2014) New Media. Oxford: Oxford University Press.

Flew T. (2018) Understanding Global Media. $2^{\text {nd }}$ ed. London: Palgrave Macmillan.

Frau-Meigs D. (2007) Cultural Diversity and Global Media Studies. Global Media and Communication 3 (3): 260-266.

Habermas J. (1991) The Structural Transformation of the Public Sphere: An Inquiry into a Category of Bourgeois Society. Massachusetts: Massachusetts Institute of Technology.

Kolker R. (2009) Media Studies: An Introduction. Oxford: John Wiley \& Sons.

Küng L., Picard R., Towse R. (eds.) (2008) The Internet and the Mass Media. London: Sage. Liebowitz S. J, Margolis S. E. (1999) Path Dependence. In: Bouckaert B., De Geest G. (eds.) Encyclopedia of Law and Economics. Ghent: Edward Elgar and the University of Ghent, pp. 981-998.

McLuhan M., McLuhan E. (1992) Laws of Media: The New Science. Toronto: Univ. of Toronto Press.

McLuhan M. (1964) Understanding Media. The Extensions of Man. New York: McGraw-Hill. McQuail D. (2010) McQuail's Mass Communication Theory. $6^{\text {th }}$ ed. London: Sage.

Miller T., Kraidy M. M. (2016) Global Media Studies. New York: Wiley.

Negroponte N. (1996) Being Digital. New York: Vintage.

Nordenstreng K., Thussu D.K. (eds.) (2015) Mapping BRICS Media. New York: Routledge. Robertson R. (1992) Globalization: Social Theory and Global Culture. London: Sage. Vol. 16. 
Rogers E. (1962) Diffusion of Innovations. New York: Free Press of Glencoe.

Thussu D. K. (2019) International Communication: Continuity and Change. $3^{\text {rd }}$ ed. London: Bloomsbury Academic.

Van der Haak B., Parks M., Castells M. (2012) The Future of Journalism: Networked Journalism. International Journal of Communication 6 (16): 2923-2938.

Williams R. (1975) Television: Technology and Cultural Form. New York: Schocken Books. 